BLS 34, No 1 2008. DOI: http://dx.doi.org/10.3765/bls.v34i1.3555

(published by the Berkeley Linguistics Society and the Linguistic Society of America)

\title{
On Shallow and Deep Minimality ${ }^{1}$
}

\author{
LEV BLUMENFELD \\ Carleton University
}

\section{Introduction}

\subsection{Minimality and stress}

Word minimality effects were one of the central discoveries of prosodic phonology (McCarthy and Prince 1986). Under the standard view, whether rule-based or couched in Optimality Theory, restrictions on the minimal size of words arise as a result of the interplay between two factors: first, in order to be pronounceable, phonological material must be parsed into prosodic categories such as stress feet, and, second, there can be constraints on the minimal size of those prosodic constituents. Together, these two factors produce the effect of a limitation on the minimal size of words which is connected with the prosodic phonology of the language. I will refer to the view that minimality and prosody are connected as the PROSODIC MINIMALITY HYPOTHESIS.

The standard theory was subject to vigorous criticism by Garrett (1999), whose typological research has shown that the relationship between the two factors is not as clean as might be expected. Garrett identifies several problematic types of word minima; a full discussion of his arguments goes beyond the scope of this brief paper. I will focus on two types of situations: languages where stressbased weight criteria do not match with the minimality-based weight criteria, and languages with a word minimum but an unbounded stress system.

The majority of languages with weight criteria mismatches between stress and minimality, as identified by Garrett, as well as by Gordon (1999), involve languages where codas are not moraic for the purposes of stress. If such a languages imposes a bimoraic word minimum, one expects to find CVV(C) words but no $\mathrm{CVC}$ or $\mathrm{CV}$ words. In fact, more often than not, minimality makes a different cut between heavy and light syllables, disallowing CV and ruling CVC in. I will discuss these cases in the next section. A smaller number of languages require monosyllables to contain вотн a long vowel and a coda, even though having just

\footnotetext{
${ }^{1}$ I am grateful to audiences at BLS and at the University of Ottawa for comments, and to Barry Alpher for discussing Pama-Nyungan phonology with me. All errors are my own.
} 


\section{Lev Blumenfeld}

one would be sufficient to satisfy the word minimum; I will come back to these cases in Section 4.

The second group of problematic languages identified by Garrett have restrictions that appear to be similar to word minima, but the stress system requires unbounded feet. One such case will be the subject of Section 2.

\subsection{CVC: light for stress, heavy for word minimum}

Languages where CVC counts as light for the purposes of stress but heavy for the purposes of minimality are numerous, according to Garrett's and Gordon's surveys. ${ }^{2}$ This mismatch is systematic, because there are no languages I am aware of with the opposite pattern, where CVC counts as light for minimality but heavy for stress. ${ }^{3}$

Such cases can in fact be brought into line with the prosodic minimality hypothesis with a simple assumption that the moraicity of codas arises as a result of constraint interaction (Morén 1999). In languages with a weight mismatch between stress and minimality, codas are non-moraic except in monosyllables, where assigning a mora to the coda would rescue subminimal inputs. Following Morén, I will refer to this idea as moraic COERCION.

Consider the following facts from Djaru, a Pama-Nyungan language (Tsunoda 1981). Djaru shows a weight mismatch: CVC counts as light for stress, but is heavy for the purposes of minimality because CVC words are attested. ${ }^{4}$ Under my proposal, the final consonants of these and only these $\mathrm{CVC}$ words are moraic, and it turns out that there is direct evidence for this proposition. Djaru has a bimoraic word minimum, as shown by lengthening of underlying CV stems: the catalyst morpheme /ya/ surfaces as [ya:] (Tsunoda 1981:46). Crucially, this lengthening does not apply to underlying CVCs, which surface with short vowels. This suggests that the $\mathrm{C}$ at the end of these preverbs is moraic.

In addition, the moraicity of the consonant in monosyllables has an effect on the ergative allomorphy. As in many other Pama-Nyungan languages, the Djaru ergative case marker is sensitive to the mora count of its base (for a survey, see

\footnotetext{
${ }^{2}$ Several cases listed by Garrett are in fact more complex, because not only are CVC monosyllables allowed while codas are in general non-moraic, but CVV words are unexpectedly excluded, in absence of any general restriction on word-final long vowels. Languages of this type include Huasteco Mayan (Larsen and Pike 1949), Luiseño (Kroeber and Grace 1960), and possibly Wintu (Pitkin 1984), where CVV words are rare. These languages appear to reverse the CVV $\gg>$ CVC $\gg\rangle$ $\mathrm{CV}$ weight hierarchy, allowing CVC but prohibiting CVV. I believe that these cases are best attributed to a root minimum similar to what I suggest for Guugu Yimidhirr below rater than to a word minimum, but there is no space here to address this fully.

${ }^{3}$ Cebuano (Shryock 1993), which is listed by Gordon as having CVV minimality but moraic codas, in fact has disyllabic minimality which is subverted by a later optional rule of intervocalic l-deletion. In the native vocabulary, all of the CVV surface words derive from CVlV inputs; loan words have CVVC minimality, similar to the Australian cases discussed below in Section 4.

${ }^{4}$ The CVC words in Djaru are the so-called 'preverbs'. While in other Australian languages such preverbs may not always be phonologically independent, Tsunoda's description makes it clear that in Djaru CVC preverbs can form phonological words of their own.
} 


\section{On Shallow and Deep Minimality}

Paster 2006a,b). The relevant allomorphs are $-(\eta g) g u$, which attaches to bimoraic stems, and $-l u$, which attaches to stems containing more than two moras (Tsunoda 1981:54-55). (The difference between - $\eta g u$ and - $g u$ has to do with the presence or absence of a nasal coda in the word; this is an OCP effect unrelated to the moracounting allomorphy). The following examples illustrate: (1)a and (1)b show the contrast between a disyllabic and a trisyllabic stem with short vowels; (1)c shows that the allomorph $-l u$, which goes on trisyllabic nouns, is also attached to nouns containing a long vowel. This shows that the allomorphy is sensitive to mora count rather than syllable count. Finally, the word in (1)d has the structure CVC.CV, and takes the allomorph that attaches to stems of two moras; this shows that codas do not contribute weight.

$$
\begin{array}{ll}
\text { a. } & \text { yaba-ygu } \\
\text { b. } & \text { manari-lu } \\
\text { c. } & \text { ga:ja-lu } \\
& \text { da:di-lu } \\
\text { d. } & \text { jambi-gu }
\end{array}
$$

'water'
'vegetable food'
'bush tomato'
'daddy'
'big'

CVC preverbs can take nominal morphology, and the ergative allomorphy corroborates my proposal that the final consonants of $\mathrm{CVC}$ are moraic. The ergative forms of two preverbs are shown in (2).

$$
\begin{aligned}
& \text { a. jud-gu-lu } \\
& \text { jud-yu-lu }
\end{aligned}
$$

The forms are irregular in two ways: first, the morpheme $-g u$ or $-\eta y u$ is attached to the CVC stem, which does not occur in any other ergative forms. ${ }^{5}$ Tsunoda suggests that this augment serves to build the stem up to the canonical disyllabic length; the choice between - $g u$ and $-\eta y u$ is unclear. However, the resulting disyllabic, bimoraic CVC.CV stem should receive the -ngu allomorph according to the normal generalizations, in the same way as the CVC.CV stem in (1)d is treated as bimoraic. Instead, the allomorph - $1 u$, reserved for trimoraic stems, is attached.

Together with the failure of vowel lengthening in underlying $\mathrm{CVC}$, the ergative allomorphy shows that the final consonant of the monosyllable is coerced to be moraic under pressure of minimality. Thus there is in fact no weight mismatch between stress and minimality.

However, not all apparent violations of the prosodic minimality hypothesis can be explained in this manner. I will argue in the remainder of this paper that in addition to prosodic factors, restrictions on the size of roots can also yield apparent minimality effects which may counteract, or be independent from, the prosody.

\footnotetext{
${ }^{5}$ There is another allomorph of the ergative, -gulu, but it attaches to stems ending in $b, g$, or $\eta$ (Tsunoda 1981:55).
} 


\section{Lev Blumenfeld}

\section{Shallow minimality: Latin}

Let me start by illustrating a classic example of prosodic minimality, which comes from Latin (Mester 1994). It is an especially clean case of the phenomenon: the prosodic minimum is exactly the same size as the minimal foot, established uncontroversially on independent grounds; the minimum is inviolable, and applies to all content and function words; and the minimum is clearly word- rather than root-based.

Based on the evidence from stress and meter, CVV and CVC are heavy; CV is light. The words in (3) below illustrate common examples of monosyllables satisfying the minimum, all of which have either a coda or a long vowel, or both.

$$
\begin{array}{lllll}
\text { nunc } & \text { 'now' } & \text { sōl 'sun' } & \text { mel 'honey' } & \text { dē 'of' } \\
\text { sunt 'be.3PL' } & \text { vīs 'force' } & \text { vir } & \text { 'man' } & \text { vì 'force.ABL' }
\end{array}
$$

Latin also has two ways of repairing subminimal inputs. The verb root/da/, when it surfaces without an affix in the imperative, undergoes vowel lengthening to satisfy the minimum (4)a. On the other hand, the three CV function words are enclitics (4)b, forming a prosodic word with their host.

\begin{tabular}{lll} 
a. & \multicolumn{3}{l}{ Lengthening } \\
ROOT & IMPER & INFIN \\
/da-/ & dā & da-re
\end{tabular}
b. Cliticization
-que 'and'
- ne 'not'
-ve 'or'

The minimum applies to function words as well as lexical words. Prepositions, conjunctions, particles, and the copula all obey the bimoraic minimum.

The stress foot of Latin is the moraic trochee: a bimoraic foot. This is an uncontroversial fact established on the basis of stress, allomorphy, and meter (Mester 1994). This means that the minimal word is identical in size to the minimal foot: Latin offers a canonical example of prosodic word minimality.

It is important to stress that the Latin requirement applies to words but not to roots. There is one verb root/da/ 'give' which consists of a light syllable; when unaffixed, it surfaces with a long vowel as shown above. The root of the verb $m e-\bar{a}-r e$ 'wander' has the same CV shape (though, due to its membership in a different morphological category, it never surfaces without the theme vowel $-\bar{a}$, and the lengthening à la (4)a never gets a chance to apply). The roots of the verbs $n-\bar{a}-r e$ 'swim' and fl-e-re 'weep' can plausibly be analyzed as consisting of only consonants, as can the root of the adverb cl-am 'secretly'. There is at least one word, $e x-\varnothing-t-a$ 'entrails', which seems synchronically not to have any root at all, being composed of the prefix ex- 'out of' and the past participle suffix $-t{ }^{6}$ Despite

\footnotetext{
${ }^{6}$ This word comes from *ex-sec-t-a 'cut out'; the root disappeared as a result of somewhat irregular phonological reduction.
} 


\section{On Shallow and Deep Minimality}

the small size of these roots, all of the WORDS derived from them have at least two moras.

To summarize: the Latin word minimum is identical to the minimal foot of the language, applies to words, both content and function, and does not apply to underlying roots. In other words, Latin offers a well-behaved example of a language with a word minimum grounded in the prosodic system of the language. I will refer to such languages as having a SHALLOW minimality effect.

\section{Deep minimality: Russian}

While Latin supplied a canonical example of shallow minimality, Russian will serve as our reference example for a different, non-prosodic type. I will show in this section that Russian has a minimum that applies to roots of content words rather than surface words, and is not prosodic in the sense that it has nothing to do with the stress system of the language.

At first glance Russian words appears to have a CCV minimality requirement, because monosyllabic content words that end in vowels must have a complex onset. The following sets of examples provide a nearly exhaustive list of such words in several morphological categories: feminine and neuter nominatives (5), genitives (6), and 1st singulars of verbs (7).

$$
\begin{aligned}
& \mathrm{CC}-\mathrm{V} \text { nom.sg. (the } \mathrm{V} \text { is a nominative marker) } \\
& \text { mg-a 'mist' tl } \mathrm{l}^{\mathrm{j}} \mathrm{a} \text { 'aphid' } \\
& \text { xn-a 'henna' mgl-a 'darkness' } \\
& \text { t'm-a 'darkness' dn-o 'bottom' } \\
& \text { mzd-a 'bribe' } \quad \mathrm{fr}^{\mathrm{j}} \text {-a 'pretentious person (pejor.)' } \\
& \text { zl-o 'evil' čm-o 'person (pejor.)' }
\end{aligned}
$$

\begin{tabular}{|c|c|c|c|c|}
\hline 'beat' & žm-u & 'press' & $\mathrm{l}^{\mathrm{j}} \mathrm{n}-\mathrm{u}$ & 'cling' \\
\hline 'weave' & $v j-u$ & 'plait' & žr-u & 'gobble' \\
\hline 'pour' & tr-u & 'rub' & šj-u & 'sew' \\
\hline 'bend' & $\mathrm{zl}^{\mathrm{j}}-\mathrm{u}$ & 'anger' & $\mathrm{mn}-\mathrm{u}$ & 'crumple' \\
\hline 'send' & žd-u & 'wait' & $\lg -\mathrm{u}$ & 'lie' \\
\hline 'trudge' & SS-u & 'piss' & rž-u & 'neigh' \\
\hline
\end{tabular}

(6) $\mathrm{CC}-\mathrm{V}$ gen.sg. of $\mathrm{CVC}$ words (the $\mathrm{V}$ is a genitive marker)

$\begin{array}{llllll}\text { vš-i 'louse' } & l^{\mathrm{j} d} \mathrm{~d}-\mathrm{a} & \text { 'ice' } & \mathrm{ps}-\mathrm{a} & \text { 'dog' } \\ \text { šv-a } & \text { 'seam' } & \mathrm{dn}^{\mathrm{j}} \mathrm{a} & \text { 'day' } & \mathrm{l}^{\mathrm{j}} \mathrm{n}-\mathrm{a} & \text { 'flax' } \\ \text { rv-a } & \text { 'moat' } & \mathrm{lb}-\mathrm{a} & \text { 'forehead' } & \mathrm{mx}-\mathrm{a} & \text { 'moss' } \\ \text { rt-a } & \text { 'mouth' } & \mathrm{l}^{\mathrm{j}} \mathrm{v}-\mathrm{a} & \text { 'lion' } & \mathrm{pn} \text {-a } & \text { 'stump' }\end{array}$

All of the monosyllables in these categories have complex onsets: there are no CV words of this kind. There seems to be a minimality requirement at play. 


\section{Lev Blumenfeld}

That the requirement for complex onsets applies only to vowel-final monosyllables is shown by the following examples. Monosyllables that end in consonants may have a simple onset or no onset at all (8)a, and the same is true of polysyllables that end in vowels (8)b. Together with (5)-(7), these data show that the complex onset requirement only applies to words that are in some sense too small.

$$
\begin{aligned}
& \text { a. sad 'garden' par 'steam' šum 'noise' } \\
& \text { um 'mind' už 'grass snake' il 'silt' } \\
& \text { b. kara 'punishment' dura 'fool (fem.)' } \\
& \text { era 'era' igo 'yoke' }
\end{aligned}
$$

The diachronic source of this peculiar restriction is clear. Many words with complex onsets like those in (5)-(7) reflect Old Russian CVCV words, where the first was a yer-one of the two short vowels, $\breve{l}$ and $\breve{u}$, which deleted if there was a non-yer vowel in the following syllable. Because Old Russian had a CVC minimum, the smallest word after yer deletion would have been CCV.

But there is more to this minimality restriction than its history. If it reflects an earlier CVC minimality that applied before yer syncope in Common Slavic, one might expect modern Russian to have a CVC minimality applying synchronically at a level prior to yer deletion. Yet this is not the case: while most of the words in (5)-(6) contain a synchronic yer, not all do. At least $x n a, t t^{j} a, f r^{j} a$, and $\check{c} m o$ unambiguously do not, as there are no alternants where the vowel shows up, and the same is true of some of the verbs in (7). This shows that the restriction has something to do with the complexity of the onset rather than with quantity of segmental material prior to yer deletion.

What is more, the minimality requirement is synchronically active. There are in fact vowel-final monosyllabic borrowings and neologisms with a simple onset, but they are NEVER INFLECTED, i.e. they are indeclinable. The following shows several examples of indeclinable CV nouns.

$$
\begin{array}{lccrrr}
\text { li } & \text { 'league' } & \text { po } & \text { 'Po (river)' } & \text { ra } & \text { 'Ra' } \\
\text { go } & \text { 'go (game)' } & \text { pa } & \text { 'pas (step)' } & & \\
\text { do, re, mi, fa, l'a, si } & \text { (names of musical notes) }
\end{array}
$$

Borrowings such as $p a$ or $p o$, even though they might inflect like feminine and neuter nouns whose citation (nominative) forms end in $-a$ and $-o$, cannot do so. Being indeclinable means that the final vowel of these CV words is part of the root rather than the nominative suffix, while in all of the inflectable words in (5)(7), the final vowel is a marker of the nominative, genitive, or 1SG. In other words, in a noun whose citation form has the shape $\mathrm{CV}$, the vowel must be part of the root, but in nouns of the shape CCV or CVCV, the vowel may be the nominative suffix. Verbs behave somewhat differently: some of the verb stems in (7) do end in a high vowel and are thus underlyingly $\mathrm{CV}$. This vowel becomes a glide when followed by a vowel in the affix: /bi $+\mathrm{u} / \rightarrow$ bju 'hit'. 


\section{On Shallow and Deep Minimality}

To sum up what we know so far: CV words may exist, but only if their vowel is part of the stem; if the final vowel of a monosyllable is part of the affix, the word must have a complex onset. This generalization appears to be due to a minimality requirement, because it is the size of the root that matters for the morphological properties of the noun. But it cannot be word minimality, because CV words are allowed (9).

In fact, the Russian data that were presented above can be understood in terms of a single minimality constraint, as long as this constraint is understood to apply to roots rather than words. The constraint requires each root to contain at least two SEGMENTS (consonants or vowels).

The following illustrates how this minimality restriction accounts for the generalizations presented thus far. Roots consisting of either a single $\mathrm{V}$ or a single $\mathrm{C}$ are predited not to exist, and are unattested (10)a. Among roots consisting of two segments, the following are attested : $\mathrm{CC}$ roots $(10) \mathrm{b}, \mathrm{VC}$ roots $(10) \mathrm{c}$, and $\mathrm{CV}$ roots (10)d, which behave differently depending on whether they are nominal or verbal. The only type predicted to exist but unattested are VV roots (10)e, but these are absent due to an independent hiatus restriction.
a. $\quad$ roots:
impossible
$\mathrm{C}$ roots:
impossible
b. CC roots:
/tl $\mathrm{j} /$ 'aphid', /xn/ 'henna'
c. $\quad \mathrm{VC}$ roots:
/ad/ 'hell', /il/ 'silt'
d. $\quad$ CV roots:
Ns: /pa/ 'step', /po/ 'Po'
(indeclinable because vowel-final)
Vs: /bi/ 'beat', /li/ 'pour' (inflected with glide formation)

e. VV roots: impossible due to an independent hiatus restriction

The biliteral minimality only applies to content (lexical) words but not to function words. There are several prepositions, conjunctions, and particles that consist of a single segment, consonant or vowel, shown below.

$\begin{array}{llllll}\text { a } & \text { 'but' } & \text { u } & \text { 'by' } & \text { s } & \text { 'with' } \\ \text { b } & \text { CONDITIONAL } & \mathrm{k} & \text { 'to' } & \text { o } & \text { 'about' } \\ \text { i } & \text { 'and' } & \mathrm{v} & \text { 'in' } & & \end{array}$

Finally and most importantly, the Russian minimality requirement is not related to the prosodic system of the language. The Russian stress system is based on unbounded feet (e.g. Halle and Idsardi 1995). There is no evidence of any kind for binary feet: no rhythmic secondary stress and no alternating vowel reduction. Thus, Russian is not expected to have any minimality requirement at all, given the 


\section{Lev Blumenfeld}

structure of its stress system. This gives further support to my argument that the constraint applies to roots rather than words. ${ }^{7}$

Let us summarize the key properties that distinguish Latin and Russian minimality. There are three. First, the level at which the minimality applies: the Latin requirement refers to the amount of material in words, while the Russian requirement counts the segments in the roots. Second, its scope: in Latin but not in Russian function words must respect minimality. And third, the relationship to prosody: in Latin but not in Russian the minimal word is related to (and identical with) the minimal foot independently motivated for the language.

In contrast to the Latin-type shallow minimality, I will refer to the constraints on the minimal size of roots as DEEP minimality. ${ }^{8}$

\section{Typological predictions}

The previous sections illustrated unambiguous examples of shallow and deep minimality. The two types have different motivations and different properties. While shallow minimality is grounded in the prosodic structure of the language, the motivation behind deep minimality is less clear, and here I will only speculate on what might give rise to limits on the minimum number of segments in roots of content words. Restrictions on roots were entertained by Gordon, as an example of "maximization of total material in a morpheme" (1999:264 and ff.), and were conjectured to be one of the motivations behind the minimality effects. Gordon, however, submits that such a view is "untenable in its strongest form", because if languages routinely maximize simply the amount of segmental material in a morpheme, ONSETS are expected to play an important part in minimality requirements, just as codas do. ${ }^{9}$ As I have argued above, however, onsets DO in fact play a role in minimality in Russian, and perhaps our failure to notice this effect is due to the independent restrictions that languages may place on onsets in addition to minima. For example, the Pama-Nyungan data that are discussed below as having deep minimality have an independent obligatory onset requirement, obscuring the effect of minimality on onsets.

I will not devote more space to speculative discussion on the motivation behind root minimality, limiting myself to the empirical observation that it exists as part of the grammar of at least some languages. ${ }^{10}$ My focus here is to harness this observation to make clearer the relationship between the typology of stress systems and minimality, arguing that some apparent mismatches between stress and minima are due to the independent action of constraints on the size of roots.

\footnotetext{
${ }^{7}$ A further argument that Russian minimality is not prosodic is that other Slavic languages with very different prosodic systems show similar minimality requirements. E.g. Czech, which has a binary stress system, also has a CCV-like word minimum (Kučera 1961, Gordon 1999).

${ }^{8}$ Hargus and Beavert (2006) offer a different case of CCV-like minimality, arguing that it applies to words and counts consonants. I cannot address these data here due to space limitations.

${ }^{9}$ See also Golston (1991) for a different view of minimal size restrictions on morphemes.

${ }^{10}$ I also leave open the question of how restrictions on roots - i.e. on inputs - are to be implemented in an output-oriented theory such as OT. This question is tangential to my main argument.
} 


\section{On Shallow and Deep Minimality}

Less is known about possible root minima than about the possible word minima. The example used above shows a segment-counting minimum: Russian requires roots to contain two segments. Some Pama-Nyungan languages require roots to contain three segments (see below). Other Australian languages have disyllabic or bimoraic root minima. As I have argued for Russian above, and as I will show for Pama-Nyungan languages below, allowing for a minimal restriction on roots brings an apparent counterexample to the prosodic minimality hypothesis into line. A natural question arises whether ANY language that appears ill-behaved from the point of view of this hypothesis can be swept under the rug of root minimality, and what would constitute a counterexample to my proposal.

The two minima are distinguishable from each other based on their properties and function in the grammar. Shallow minimality applies to words and is prosodically natural. Characteristic of shallow minima are cases where special phonological or morphological augmentation processes bring subminimal roots up to the required surface minimum. Vowel lengthening in monosyllables in Latin and Djaru is an example of such phonological augmentation. There can also be minimality-driven blocking of a deletion rule. E.g. in Djapu final vowel deletion applies only in words longer than two syllables (Morphy 1983:29-30). A similar effect is observed in Lardil (Hale 1973). Strategies that aim to satisfy a shallow minimum can also be morphological: in some Australian languages where the minimum is disyllabic but verb roots can consist of just one CV syllable, allomorphy can ensure that verbs derived from these roots never surface with fewer than two syllables. Djapu (Morphy 1983), Nyawaygi (Dixon 1983), Uradhi (Crowley 1983), and Wajarri (Douglas 1981), are examples of such languages.

On the other hand, if a language's minimum is due to a restriction on roots (a deep minimum), then there should not be any such augmentation effects, because morphological affiliation of segments is non-negotiable, and increasing the amount of material in surface words does nothing to increase the size of the underlying root.

A language can be unambiguously diagnosed as having a shallow minimality restriction, if it has the kind of minimality-driven augmentation of subminimal inputs. My proposal makes the following typological prediction: if a language has shallow minimality, then the word minimum ought to have the connection with the prosodic system of the language as predicted by the standard prosodic minimality hypothesis (modulo complications such as coercion). The equivalent converse prediction is that if a minimum demonstrably has nothing to do with the prosodic system of the language (as in Russian), it must be due to a restriction on the size of roots rather than words, and should behave accordingly: there should not be any augmentation processes, for example.

A counterexample to the theory proposed here would be a language with a minimality requirement that unambiguously applies to words, but does not appear to be rooted in the prosodic system of the language.

Finally, there is a caveat to be added. It might be tempting to suggest that shallow minimality should always be surface-true - because, after all, it applies to 


\section{Lev Blumenfeld}

words - while deep minimality need not necessarily be satisfied on the surface. There are several counterexamples to this proposition. Anguthimri (Crowley 1981) has a bimoraic word minimum, and a Latin-like lengthening process that ensures that $/ \mathrm{CV} /$ inputs surface with long vowels (12)a. There is also schwainsertion that applies before word-initial voiced fricatives and [r]. This rule applies AFTER minimality-driven lengthening (12)b. The fact that the minimum is evaluated at a level of representation other than the surface form does not make it any less of a shallow, or prosodic, word minimum. The minimality-driven lengthening is simply counterbled by a later process.

$$
\begin{array}{llll}
\text { a. } & / \mathrm{pwi} / & \text { fwi: } & \text { 'seed' } \\
& / \mathrm{wa} / & \text { wa: } & \text { 'grey hair' } \\
\text { b. } & / \mathrm{tu} / & \text { tu: } & \text { 'west' } \\
\text { ba } & \text { əra: } & \text { 'stomach' }
\end{array}
$$

\section{Intersection of deep and shallow minimality}

In the languages discussed so far, the minimum was either shallow or deep. In this section I argue that an apparent set of counterexamples to the prosodic minimality hypothesis from several Pama-Nyungan languages is due to the combined effects of the two kinds of minimality.

Most Pama-Nyungan languages have either disyllabic or bimoraic minimality (e.g. Dixon 2002). Strict disyllabic minima tend occur in languages where final stress is impossible (Garrett 1999; see also Kager 1995), but the details of the distribution of disyllabic vs. bimoraic minima are complex and go beyond the scope of this paper.

What interests us here are cases where the minimum is neither disyllabic nor bimoraic. A number of languages have the following restriction: monosyllables are only allowed if they contain ВОTH a long vowel and a coda, a restriction I will refer to as a SUPERMINIMUM. For example, Guugu Yimidhirr (Haviland 1979) and Gumbayngirr (Eades 1979) both have this restriction. In Yimidhirr, the following monosyllables occur: bu:r 'nest', mi:l 'eye', and $d u: l$ 'guts', but there are no CVV ones in the lexical vocabulary.

Crucially, neither Yimidhirr nor Gumbaynggir has moraic codas, nor a prohibition against word-final vowels. Thus the CVVC minimum cannot be explained as a case of either coercion or ordinary phonotactics, and presents a genuine counterexample to the prosodic minimality hypothesis. One interpretation of these facts is that these languages have вОтн a shallow and a deep minimality requirement at the same time: the shallow requirement is bimoraic and ensures that the word contains two moras at surface, while the deep requirement requires noun roots to contain at least THREE segments. ${ }^{11}$ Thus a CVV word would violate the deep minimum, a CVC word the shallow minimum, and CV word would violate both. Only CVVC has both two moras and three segments.

\footnotetext{
${ }^{11}$ Assuming, uncontroversially, that a long vowel counts as a single segment.
} 


\section{On Shallow and Deep Minimality}

If languages like Guugu Yimidhirr are treated as having вотн shallow and deep minimality at the same time, they do not present a counterexample to the prosodic minimality hypothesis.

\section{Conclusion}

The prosodic minimality hypothesis imposes expectations on the relationship between minimality and stress which do not always correspond to the observed typology. Some of the mismatches between stress and minimality can be analyzed as due to moraic coercion. Other cases are due to restrictions on roots, which are independent of the prosodic system of the language. A theory that allows both shallow (word) and deep (root) minimality has a better match with the typology.

\section{References}

Crowley, Terry. 1981. The Mpakwithi Dialect of Anguthimri. In R.M.W. Dixon and Barry Blake, eds., 147-194.

Crowley, Terry. 1983. Uradhi. In R.M.W. Dixon and Barry Blake, eds., 307-428.

Dixon, R. M. W. 1983. Nyawaygi. In R.M.W. Dixon and Barry Blake, eds., 431525.

Dixon, R. M. W. 2002. Australian Languages: Their Nature and Development. Cambridge: Cambridge University Press.

Dixon, R. M. W. and Barry Blake, eds. 1979. Handbook of Australian Languages, Volume I. Amsterdam: John Benjamins.

Dixon, R. M. W. and Barry Blake, eds. 1981. Handbook of Australian Languages, Volume II. Amsterdam: John Benjamins.

Dixon, R. M. W. and Barry Blake, eds. 1983. Handbook of Australian Languages, Volume III. Amsterdam: John Benjamins.

Douglas, Wilfrid H. 1981. Watjarri. In R.M.W. Dixon and Barry Blake, eds., 197272.

Eades, Diana. 1979. Gumbaynggir. In R.M.W. Dixon and Barry Blake, eds., 245361.

Garrett, Edward. 1999. Minimal Words Aren't Minimal Feet. In Matthew K. Gordon, ed., Papers in Phonology 2: UCLA Working Papers in Linguistics, Vol.1., 68-105. Los Angeles: University of California, Los Angeles, Department of Linguistics.

Golston, Chris. 1991. Minimal Word, Minimal Affix. North East Linguistic Society 21:95-109.

Gordon, Matthew. 1999. Syllable Weight: Phonetics, Phonology, and Typology. $\mathrm{Ph} . \mathrm{D}$. diss., University of California, Los Angeles.

Hale, Kenneth. 1973. Deep-surface Canonical Disparities in Relation to Analysis and Change: An Australian Example. In Thomas A. Sebeok, ed., Current Trends in Linguistics. Volume 11: Diachronic, Areal, and Typological Linguistics, 401-458. The Hague: Mouton. 
Lev Blumenfeld

Halle, Morris and William Idsardi. 1995. General Properties of Stress and Metrical Structure. In John A. Goldsmith, ed., The Handbook of Phonological Theory, 403-444. Oxford: Blackwell.

Hargus, Sharon, and Virginia Beavert. 2006. Word-initial Clusters and Minimality in Yakima Sahaptin. Phonology 23:21-58.

Haviland, John. 1979. Guugu Yimidhirr. In R.M.W. Dixon and Barry Blake, eds., $27-180$.

Hayes, Bruce P.. 1995. Metrical Stress Theory: Principles and Case Studies. Chicago: University of Chicago Press.

Kager, René. 1995. Consequences of Catalexis. In Harry van der Hulst and Jeroen van de Weijer, eds., Leiden in Last: HIL Phonology Papers I, 269-298. The Hague: Holland Institute of Generative Linguistics.

Kroeber, A.L. and Goerge William Grace. 1960. The Sparkman Grammar of Luiseño. Berkeley: University of California Press.

Kučera, Henry. 1961. The Phonology of Czech. The Hague: Mouton.

Larsen, Raymond S. and Eunice Victoria Pike. 1949. Huasteco Intonations and Phonemes. Language 25(3):268-277.

McCarthy, John J. and Alan Prince. 1986. Prosodic Morphology. Ms., University of Massachusetts at Amherst.

Mester, R. Armin. 1994. The Quantitative Trochee in Latin. Natural Language and Linguistic Theory 12:1-61.

Morén, Bruce T. 1999. Distinctiveness, Coercion, and Sonority. Ph.D. diss., University of Maryland at College Park.

Morphy, Frances. 1983. Djapu, a Yolngu Dialect. In R.M.W. Dixon and Barry Blake, eds., 1-188.

Paster, Mary. 2006a. Pama-Nyungan Ergative Allomorphy: Historical Reconstruction and Theoretical Consequences. Presentation, Annual Meeting of the Linguistic Society of America.

Paster, Mary. 2006b. Phonological Conditions on Affixation. Ph.D. diss., University of California, Berkeley.

Pitkin, Harvey. 1984. Wintu Grammar. Berkeley: University of California Press.

Shryock, Aaron. 1993. A Metrical Analysis of Stress in Cebuano. Lingua 91:103148.

Tsunoda, Tasaku. 1981. The Djaru Language of Kimberley, Western Australia. Canberra: The Australian National University.

School of Linguistics and Applied Language Studies

Carleton University

1125 Colonel By Dr.

Ottawa ON K1S 5B6

Canada

lev_blumenfeld@carleton.ca 